\title{
SIGNIFICANCE OF SUB-CRITERIA IN MEASURING SUSTAINABLE PERFORMANCE OF BUILDING ENVELOPE DEVELOPMENT
}

\author{
ABRAHAM MWASHA, RUPERT G. WILLIAMS \& JOSEPH IWARO \\ Department of Civil and Environmental Engineering, University of West Indies, \\ St. Augustine Campus, Trinidad and Tobago.
}

\begin{abstract}
Currently, several building performance assessment methods are in use around the world but these methods fail to incorporate the needed sustainable energy performance indicators and sub-criteria, thus the necessity of current lack of capability to determine the actual sustainable performance of building envelope. Besides, aggregate criteria are extremely complex to create and are often criticized for simplifying the complex issues of sustainability into one performance issue. The aim of this paper is to create more effective sub-criteria that can be assessed under these sustainable energy performance indicators and influence the capability of building performance assessment methods. To create these sub-criteria, a comprehensive survey of the construction industry professional was conducted using a questionnaire technique while the data was analyzed using correlation and regression analysis techniques. Suggestions were made on those sub-criteria that should be assessed under the sustainable performance indicator to be incorporated into a sustainable performance model for the buildings' envelope development.
\end{abstract}

Keywords: Building, efficiency, energy, envelope, environmental, indicator, material, performance, sub-criteria, sustainable.

\section{INTRODUCTION}

Today, great deal of effort is being placed all over the world in achieving sustainable performance in the construction industry. Such efforts can be seen in the area of passive building, building performance assessment and standards [1-3]. The objectives of these efforts are to regulate the energy consumption and to ensure building sustainability in extreme climatic condition and sustainable efficiency design in building. These objectives can only be achieved through assessing the actual sustainable performance of the building and envelope using appropriate building assessment tool [1-3]. Moreover, the rapid growth of energy use, worldwide, has already raised concerns over the problem of supply, the exhaustion of energy resources and severe environmental impacts (ozone layer depletion, global warming, climate change etc.) that are affecting the building sustainability $[4,5]$. Besides, the fact that the integration of indicators in the existing building assessment methods is limited, the residential building envelope sustainable performance was not accounted for in those methods. Therefore, building designers can contribute to solving the energy consumption problem if proper early design decisions are made regarding the sustainable building envelope and integration of sustainable building envelope materials [6-8]. As a result, efforts to improve building energy efficiency should not only concentrate on the design of the air conditioning system but also include the sustainable building envelope [9]. Numerous demands are placed on the building envelope as the energy interface between the ambient conditions and the internal climate needs of users and occupants [10]. Thus the necessity of this study to address the complexity surrounding the determination of essential sub-criteria for building envelope sustainable performance assessment. 


\section{PREVIOUS RESEARCHES ON THE SUSTAINABLE PERFORMANCE OF BUILDING ENVELOPE}

Sustainable performance of building development is being more widely adopted around the world to reduce energy costs and improve the well-being of occupants. The adoption of sustainable performance of building development is increasing globally due to the need for reducing resource consumption and contamination during a building's life cycle [11]. In response to the demand for sustainable performance assessment, evaluation and management of buildings' environmental performance, several tools and methodologies have been developed and are being implemented in the construction sector aiming at sustainable performance of building developments. Papadopoulos and Giama $[12,13]$ worked on environmental management tools emphasizing on rating systems' analysis. In their research work, Leadership in Energy and Environmental Design (LEED) and Building Research Establishment Environmental Assessment Method (BREEAM) guides for existing buildings and new construction were compared while the similarities and differences were analyzed and a joint matrix for existing buildings' evaluation was created as a result of the rating systems' analysis. Despite the analogies and similarities existing between them, there are differences, which may lead to deviations in the results of an evaluation. Thus it indicates the complexity with criteria used in rating systems being developed. In another development, Mwasha et al. [3] stresses the role of criteria in modeling the sustainable performance of building envelope. In their study, they presented a method to develop main criteria for modeling the sustainable performance of building envelope. But the issue of sub-criteria was not addressed. Hill and Bowen's study adopted another four attributes to promote sustainable performance in construction, including social, economic, biophysical, and technical aspects [14]. According to this study, social sustainability is to improve the quality of human life, to implement skills training and capacity enhancement of the disadvantaged, to seek fair or equitable distribution of construction social costs, and to seek intergenerational equity. The economic sustainability is to ensure financial affordability to the intended beneficiaries, to promote employment creation; to enhance competitiveness, to choose environmentally responsible suppliers and contractors, and to maintain capacity to meet the needs of future generations. The biophysical sustainability is to extract fossil fuels and minerals at rates which are not faster than their slow redeposit into the Earth's crust, to reduce the use of four generic resources (namely, energy, water, materials, and land); to maximize resource reuse and/or recycling; to use renewable resources in preference to nonrenewable resources, to minimize air, land and water pollution, to maintain and to restore the earth's vitality and ecological diversity; and to minimize damage to sensitive landscape. The technical sustainability is to construct durable, reliable, and functional structures; to pursue quality in creating built environment; to humanize large buildings; and to infill and revitalize the existing urban infrastructure. Other studies presented methods to mitigate barriers in implementing environmental management in construction toward achieving a better sustainability performance [2, 15-19]. However, fragmentation in using these principles cannot achieve satisfactory results. Different participants often practice in isolation and emphasize their individual viewpoints. There is a lack of methodology to help all building projects working in a consistent and cooperative environment toward the same goal for achieving better project sustainable performance.

Following the wide acceptance of the sustainable development notion, finding an accurate way to assess and measure sustainability levels of existing and future developments has become an important issue [20]. There have been various studies which have proposed different methods for sustainability assessment [21-23]. A thorough review of some of these assessment tools are presented by Karol and Brunner [24], particularly scrutinizing six key neighborhood's scale sustainability assessment tools. Although there are various sustainability assessment methodologies, models, and tools developed so far, only a few have an integral approach that takes into account all 
of the environmental, energy, economic, and social aspects. According to Singh et al. [25]. in most cases, the focus is on one of the three aspects. Although, it could be argued that they could serve supplementary to each other, sustainability is more than an aggregation of the important issues, it is also about their inter-linkages and the dynamics developed in a system. This point will be missing if tried to use them as supplementary and it is one of the most difficult parts to capture and reflect in measurements [26]. Hacking and Guthrie [27] advocates that the confusion inherent in sustainability assessment methods might be avoided by gathering all these methods under a broad umbrella of sustainability assessment appraisal and forming a more precisely defined method based on sustainability indicators. The literature indicates limitations of the existing sustainable assessment models and sustainable development requests, which are rapidly increasing in sophistication, and this creates an urgent need for more effective assessment methods and tools [28]. Particularly in the area of building envelope sustainable performance assessment is lacking. Thus, necessitates the current study to elaborate and clarify some of the limitations by creating more effective sub-criteria indicators that can be assessed under sustainable energy performance indicators to be incorporated into sustainable performance assessment model and that can influence the capability of building performance assessment methods.

\section{METHODOLOGY}

Based on the literature reviewed and the outcome from the sustainable energy performance indicator survey conducted by Mwasha et al. [3], a questionnaire was designed and developed to survey experts' opinions on sub-criteria to be assessed under sustainable energy performance indicators. The questionnaire was divided into three main sections. The first section collected information pertaining to general details about the respondents such as their position in the organization, type of organization and client type etc. The second section collected information on the rating of energy efficiency sub-criteria and material efficiency sub-criteria using a scale of 1 to 5 , from least importance ' 1 ' to most importance ' 5 '. Likewise, the third section collected experts' opinions on the environmental impact sub-criteria, external benefit sub-criteria, and regulation efficiency sub-criteria. The survey was conducted in two phases. First, to standardize the questionnaire before it was fully sent out, a pilot study was conducted to test the questionnaire. The pilot questionnaire was sent out in September 2010 to 45 professionals who are construction management postgraduates from University of West Indies working in different organization in Trinidad and Tobago and construction managers who are graduates from this program. A total of 30 completed questionnaires were returned in the first phase of the survey, representing a $67 \%$ response rate. The feedback from the pilot study was analyzed and some comments and criticisms were incorporated, leading to substantial adjustments to the original questionnaire draft. The questionnaire was adjusted before the final extensive questionnaire survey was carried out. Following the pilot study, an extensive questionnaire was carried out. A total of 350 questionnaires were sent to construction and building professionals working in different organizations in Trinidad and Tobago construction sector by post and personal delivery in October, 2010.These participants were from both private and public organizations as well. Thereafter, follow-up reminders were also sent together with personal visitation, which led to the return of 120 completed questionnaires by the end of November 2010 representing a $34 \%$ response rate. This response rate is acceptable for research of this type just as response rate of this nature is inevitable [29]. Data was compiled for further analysis. The summary of survey distribution and return is presented in Table 1 below.

\section{DATA PRESENTATION AND ANALYSIS}

The analysis of the returned questionnaires showed that $75 \%$ of the respondents are from private sector, while $45 \%$ are from public sector working for government. There is a significant improvement 
Table 1: Distribution of survey participants.

\begin{tabular}{lcclcccccc}
\hline Results & Const & Arch & Cont & Eng & Env & PM & QS & Others & Total \\
\hline Sent & 45 & 15 & 75 & 100 & 35 & 45 & 15 & 20 & 350 \\
Returned & 10 & 5 & 24 & 35 & 12 & 20 & 6 & 8 & 120 \\
\% of total & 8.3 & 4.2 & 20.0 & 29.2 & 10 & 16.7 & 5.0 & 6.6 & 100 \\
\hline
\end{tabular}

Note: Arch - Architects; PM - Project Managers; Cont - Contractors; QS - Quantity Surveyors; Const - Consultants; Eng - Engineers; Env - Environmentalists; Others - included land surveyors and developers.

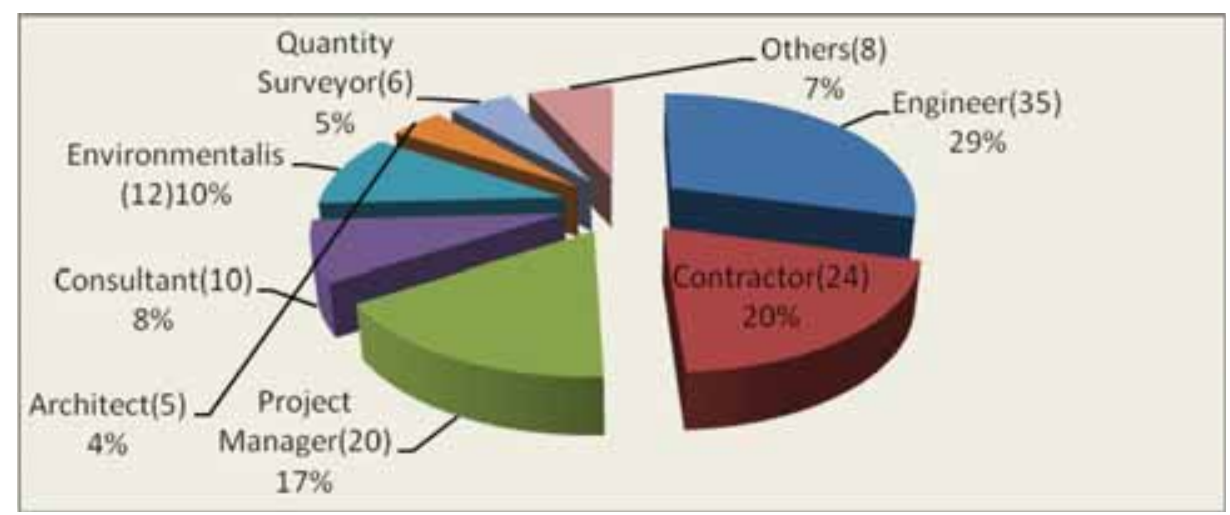

Figure 1: Distribution of respondents by professions (total $=120$ ).

from the public participation as compared to sustainable energy performance indicator survey [3]. In Trinidad and Tobago, construction sector is dominated by private firms which still necessitate more professionals working in the private sector. Therefore, the respondents' views obtained from this survey show more of private sector opinions. Moreover, Fig. 1 shows the distribution of respondents by professions. The response rate of engineers, project managers, and contractors constituted $66 \%$ while the remaining $34 \%$ were distributed among architects, environmentalist, consultants, and others.

Thus it shows that the outcome obtained from the survey represents the opinion of building professionals likely with wealth of knowledge and experience needed in identifying sustainable performance sub-criteria to be assessed for those sustainable performance indicators to be included in the model. In the figures below, the relative importance index (RII) was computed for all performance criteria tested based on the building and construction professional responses. The computational procedures were as stated in section below. In order to rank these indicators according to their importance, the total weight for each indicator is calculated while a RII is constructed reflecting the level of importance of these indicators using the formula [30].

$$
\mathrm{RII}=\frac{\sum_{\mathrm{i}=1}^{\mathrm{n}} \mathrm{Wi}}{\mathrm{AN}}
$$

where $\mathrm{RII}=$ relative important index, $\mathrm{W}=$ weighting as assigned by each respondent on a scale of one to five where one implying 'least important' and five 'most important', $\mathrm{A}=$ the highest weight (5), 
$\mathrm{N}=$ the total frequency in the sample. The rankings of the indicators are computed on the basis of the RIIs computed for each indicator. The weighted average of the RIIs for each indicator identified is computed by combining all the RIIs and finding the average weighted RIIs by summing the products of the RIIs for each group with the proportion of respondents from the corresponding group. Likewise, respondents were asked to rate sub-criteria considered important for sustainable building envelope development on a scale of one to five where a score of one represents the least important and a score of five represents the most important. The ranking of the energy efficiency, material efficiency, environmental impact, and external benefit and regulation efficiency sub-criteria are presented in tables and figures below.

\subsection{Energy efficiency}

The ranking in Table 2 identifies total energy consumption with 0.90 RII index as the most important issue for building envelope sustainable performance assessment under energy efficiency indicator. This is closely followed by energy conservation, $0.88 \mathrm{RII}$ index, energy subsidies, $0.87 \mathrm{RII}$ index, window

Table 2: Weighted RII of energy efficiency sub-criteria.

\begin{tabular}{|c|c|c|c|c|c|c|c|c|c|}
\hline \multirow[b]{2}{*}{$\begin{array}{l}\text { Energy efficiency } \\
\text { sub-criteria }\end{array}$} & \multicolumn{9}{|c|}{ Weighted RII } \\
\hline & Eng & Cont & PM & Env & Const & Arch & QS & Others & $\begin{array}{c}\text { Average } \\
\text { weighted } \\
\text { RII }(\%)\end{array}$ \\
\hline Building envelope design & 0.79 & 0.59 & 0.59 & 0.60 & 0.60 & 0.92 & 0.50 & 0.58 & 0.66 \\
\hline Energy consumption & 0.95 & 0.86 & 0.90 & 0.88 & 0.90 & 0.68 & 0.93 & 0.90 & 0.90 \\
\hline Energy conservation & 0.90 & 0.78 & 0.89 & 0.83 & 0.86 & 0.84 & 0.80 & 0.93 & 0.86 \\
\hline $\begin{array}{l}\text { Building equipment and } \\
\text { appliance }\end{array}$ & 0.72 & 0.61 & 0.62 & 0.73 & 0.66 & 0.72 & 0.63 & 0.63 & 0.67 \\
\hline Wall insulation & 0.85 & 0.75 & 0.78 & 0.80 & 0.84 & 0.80 & 0.77 & 0.75 & 0.80 \\
\hline $\begin{array}{l}\text { Energy subsidies } \\
\text { and policy }\end{array}$ & 0.86 & 0.82 & 0.89 & 0.88 & 0.90 & 0.88 & 0.87 & 0.88 & 0.87 \\
\hline $\begin{array}{l}\text { Depletion of renewable } \\
\text { resources }\end{array}$ & 0.71 & 0.62 & 0.67 & 0.70 & 0.64 & 0.60 & 0.63 & 0.60 & 0.66 \\
\hline $\begin{array}{l}\text { Depletion of non-renewable } \\
\text { resources }\end{array}$ & 0.73 & 0.61 & 0.66 & 0.70 & 0.66 & 0.52 & 0.57 & 0.60 & 0.66 \\
\hline Door and window frame & 0.82 & 0.70 & 0.72 & 0.82 & 0.74 & 0.44 & 0.60 & 0.80 & 0.74 \\
\hline Climate change & 0.65 & 0.58 & 0.56 & 0.60 & 0.52 & 0.40 & 0.40 & 0.50 & 0.57 \\
\hline Technological development & 0.66 & 0.49 & 0.55 & 0.58 & 0.56 & 0.36 & 0.47 & 0.48 & 0.56 \\
\hline Operational energy & 0.85 & 0.78 & 0.83 & 0.82 & 0.78 & 0.88 & 0.77 & 0.75 & 0.81 \\
\hline Window and door glazing & 0.86 & 0.77 & 0.81 & 0.78 & 0.84 & 0.80 & 0.80 & 0.83 & 0.82 \\
\hline Labeling and certification & 0.73 & 0.63 & 0.61 & 0.60 & 0.74 & 0.72 & 0.67 & 0.58 & 0.66 \\
\hline
\end{tabular}

Note: RII for each building professional is computed as total score divided by the total number in the sample multiplied by the highest weight (5). For instance the RII of building envelope design for engineer (eng) was computed as $131 /(35 \times 5)=0.79$; the average weighted RII was computed as: $0.79 \times 35 / 120+0.59 \times 24 / 120+0.59 \times 20 / 120+0.60 \times 12 / 120+0.60 \times 10 / 120+0.92 \times$ $5 / 120+0.50 \times 6 / 120+0.58 \times 8 / 120=0.66$. 
and door glazing, 0.82 RII index, operational energy, 0.81 RII index, wall insulation, 0.80 RII index and door and window frame, 0.74RII index. All these factors mentioned above are considered relatively important for sustainable performance assessment because their weighted RII index is relatively high average as indicated from expert opinion survey. However, other sub-criteria such as building envelope design, building appliance and equipment, labeling and certification, depletion of renewable resources and depletion of non-renewable resources with their average weighted RII index ranging from 0.66 to 0.67 are also considered very important in assessing the sustainable performance of building envelope. Besides, their average weighted RII is relatively high and worthy of consideration.

This finding suggests that for energy performance to be adequately assessed in the building envelope sustainable performance assessment, all these above-identified energy efficiency issues based on the weighted RII index performance are important sub-criteria that must be assessed under energy efficiency indicator in building envelope sustainable performance assessment. Generally, this finding indicates high level of energy efficiency awareness among the respondents and further justified the importance of incorporating energy efficiency indicator in the integrated sustainable performance model.

\subsection{Material efficiency sub-criteria}

The sub-criteria of material efficiency investigated on this research were presented in Fig. 2. In the analysis, durability came first with 0.83 average weighted RII index, closely followed by recycling

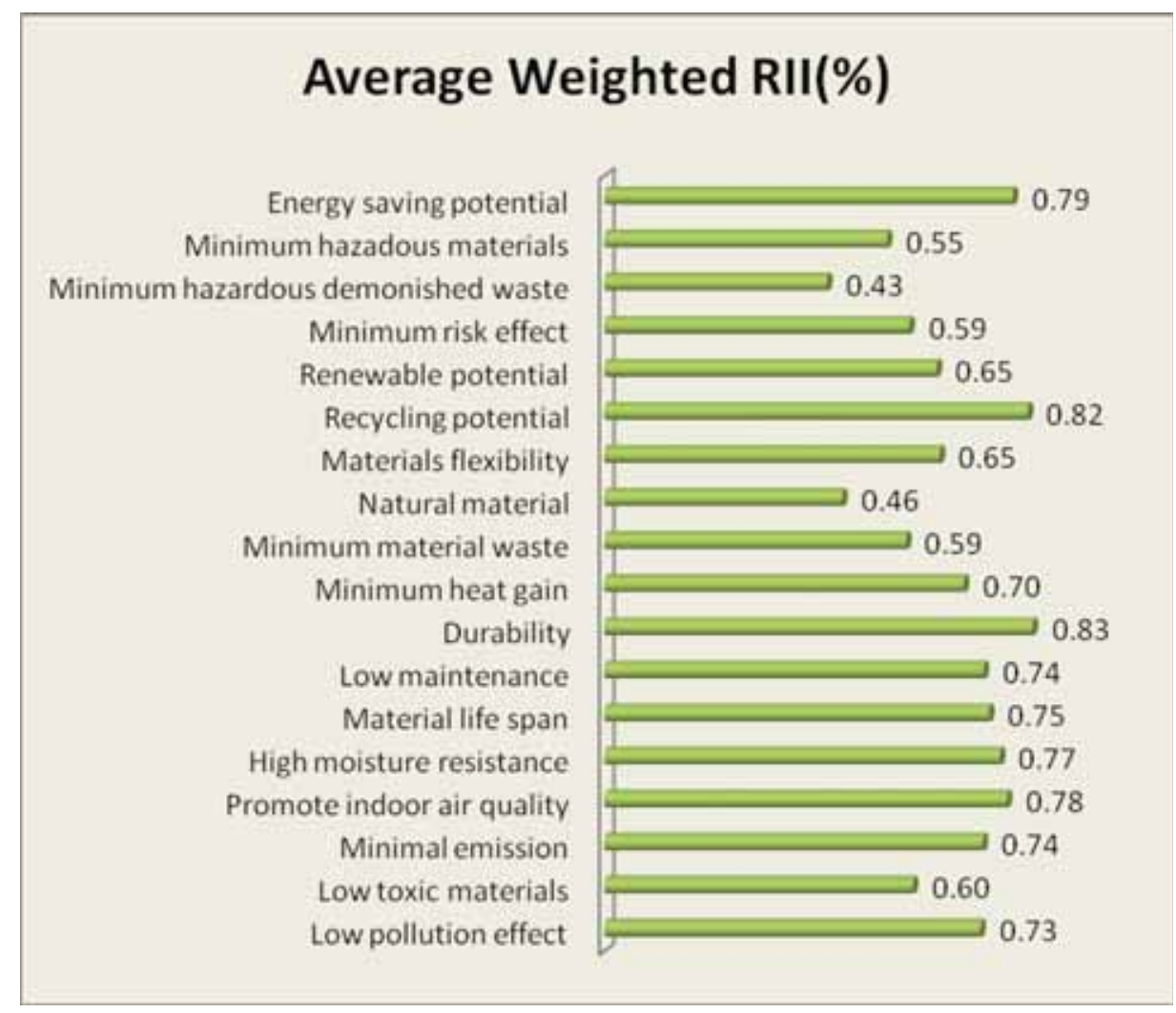

Figure 2: Ranking of average weighted RII (\%) for material efficiency sub-criteria. 
potential with 0.82 RII index, energy saving potential, 0.79 RII index, promote indoor air quality, $0.78 \mathrm{RII}$ index, high moisture resistance, $0.77 \mathrm{RII}$ index, material life span, $0.75 \mathrm{RII}$ index, low pollution effect, 0.73 RII index, minimal emission, 0.74 RII index, low maintenance with 0.74 RII index, and minimum heat gain, $0.70 \mathrm{RII}$ index. Other sub-criteria identified along with the above criteria based on their relatively high average weighted RII index are renewable potential, 0.65 RII index and material flexibility, 0.65 RII index.

The finding from this investigation suggests that durability is considered the most important subcriteria that must be assessed during building envelope sustainable performance assessment. However, for the envelope to be sustainable, other material efficiency issues have to be taken into consideration as well in the assessment such as recycling potential of envelope materials, energy saving potential, potential to improve indoor air quality, high moisture resistance, material life span, low pollution effect, minimal emission, low maintenance, minimum heat gain, renewable potential, and material flexibility. These were the essential sub-criteria identified based on the expert opinions and weighted RII computed to show their importance. Hence, the finding from this investigation as shown in Fig. 2 has identified those essential criteria that must be assessed under material efficiency indicator in building envelope sustainable performance assessment. Also, the finding suggests high level of material efficiency awareness among the respondents and further establishes the need to incorporate material efficiency and the identified sub-criteria into the integrated sustainable performance model.

\subsection{Environmental impact}

Furthermore, Fig. 3 presents the relative index performance of environmental impact issues investigated on this research. The analysis from Fig. 3 reveals their ranking and the level of their importance to sustainable performance of building envelope. Based on the expert rating as analyzed in Fig. 3 below, air pollution came first with 0.87 average weighted RII index, closely followed by material emission, 0.77 index, depletion of renewable resources, 0.75 index, energy consumption, 0.74 index, deforestation impact, 0.73 index, depletion of non-renewable resource, 0.72 index, construction waste, 0.72 index, indoor air quality, 0.72 index, carbon emission, 0.70 index, and noise pollution, 0.67 index. The result from Fig. 3 clearly identified those essential sub-criteria that must be assessed under environmental impact indicator in building envelope sustainable performance assessment. The higher rate of weighted RII recorded on the identified sub-criteria suggest high level of agreement, awareness and interest from respondents. Thus it indicates the importance of incorporating environmental impact performance indicator and the identified sub-criteria into the integrated sustainable performance model.

\subsection{External benefit}

In addition, external benefit issues were analyzed in Fig. 4 below to rank the level of their importance to building envelope sustainable performance based on expert opinions. According to Fig. 4, indoor air quality came first with 0.87 average weighted RII, closely following by environmental ecological value with 0.84 average weighted RII index, landscape beautification, 0.73 index, environmental economical value, 0.72 index, social image, 0.71 index, local community economy, 0.70 index, indoor environment, 0.70 index, environment beautification, 0.69 index, user productivity, 0.68 index, and living environment, 0.68 index. In view of their average weighted RII index performance, these identified external benefit issues are considered as those important sub-criteria to be assessed for external benefit sustainable performance indicator. Their weighted RII index is high, 


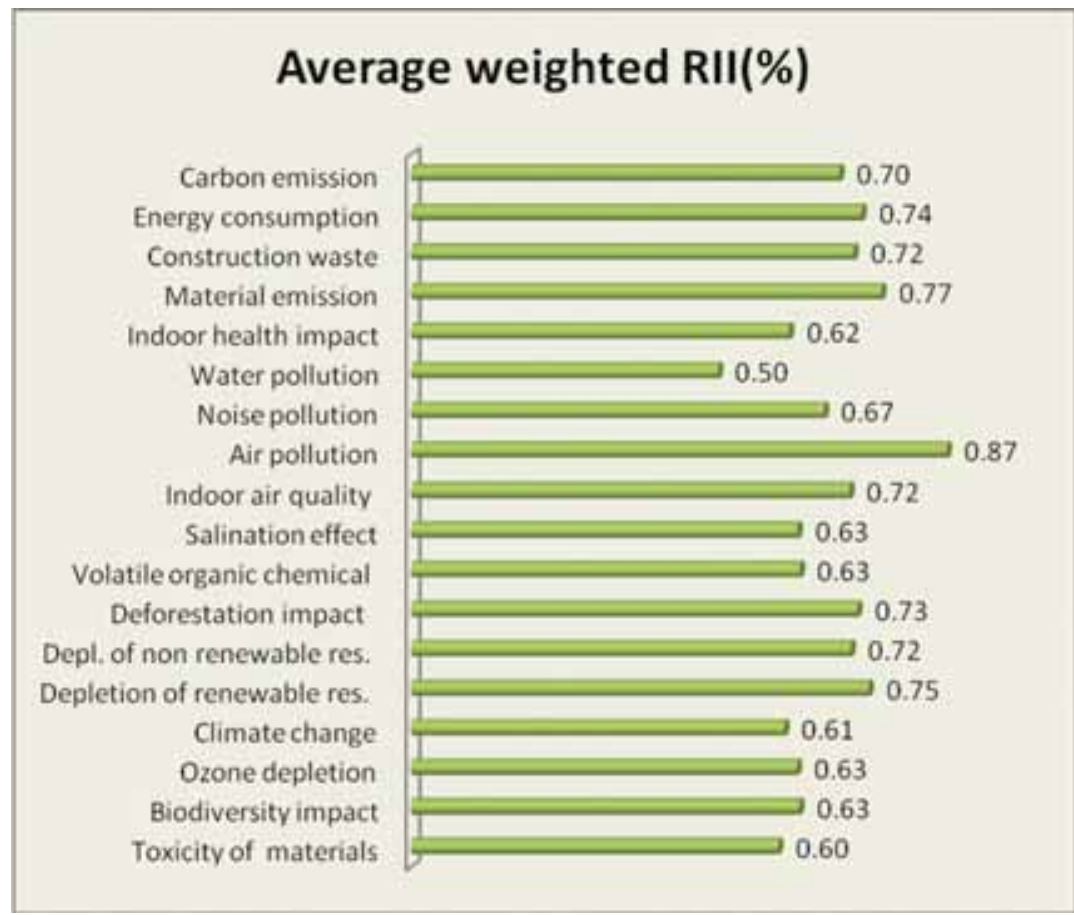

Figure 3: Ranking of average weighted RII (\%) for environmental impact sub-criteria.

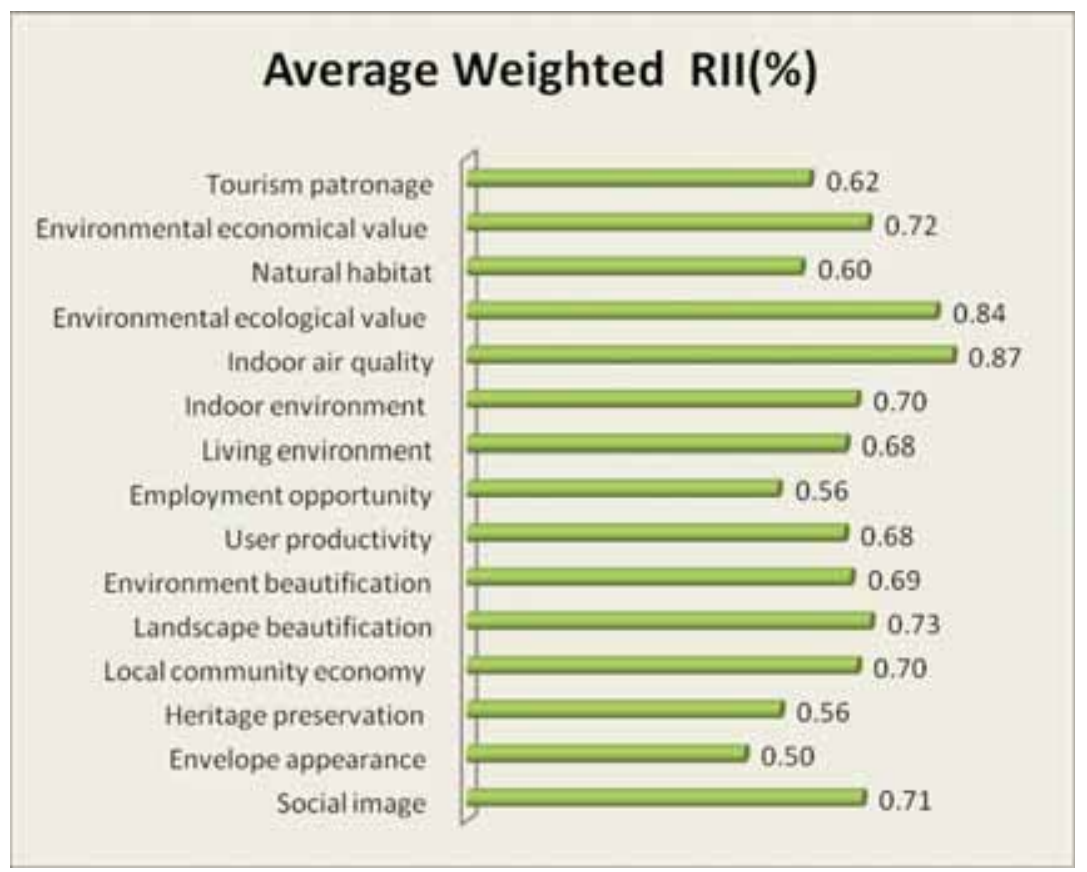

Figure 4: Ranking of average weighted RII (\%) for external benefit sub-criteria. 
which suggests high level of agreement from respondents. Thus it further suggests that these subcriteria must be adequately assessed when assessing external benefit performance for building envelope sustainable performance. More importantly, this finding suggests high level of external benefit awareness among the respondents and establishes the need to incorporate external benefit performance indicator in the integrated sustainable performance assessment model. External benefit comprises: social benefits, material efficiency benefits, and environmental benefits. Finally, the relative index performance of regulation efficiency issues was further investigated on this research. The purpose of this section is to identify those sub-criteria under energy regulation efficiency to be assessed for sustainable performance of building envelope.

Similar analysis conducted on regulation efficiency shown in Fig. 5 suggested moisture resistance as the most important sub-criteria under energy regulation efficiency for assessing sustainable performance of building envelope with average weighted RII index of 0.83 , followed by construction quality with 0.81 average weighted RII index, energy consumption, 0.73 index, heat loss, 0.71 index, air tightness, 0.71 index, $\mathrm{CO}_{2}$ emission, 0.70 index, design flexibility, 0.69 index, and regulation compliance, 0.67 index. In view of their average weighted RII index performance as shown above, the average weighted RII index recorded by these identified sub-criteria under energy regulation is relatively comparable with other sustainable indicators analyzed. These identified regulation issues that must be assessed for building envelope sustainable performance. The high level of average weighted RII index recorded by these sub-criteria under energy regulation suggests high level of agreement from respondents on the identified energy regulation sub-criteria. More importantly, this finding suggests high level of energy regulation awareness among the respondents and establishes the need to incorporate energy regulation efficiency performance indicator in the integrated sustainable performance assessment model. In general, the average weighted RII index as obtained in this study is high, relatively close to each other and above 0.60 overall averages RII index. Thus it suggests that all sub-criteria identified in this investigation are important and must be adequately assessed for building envelope sustainable performance assessment.

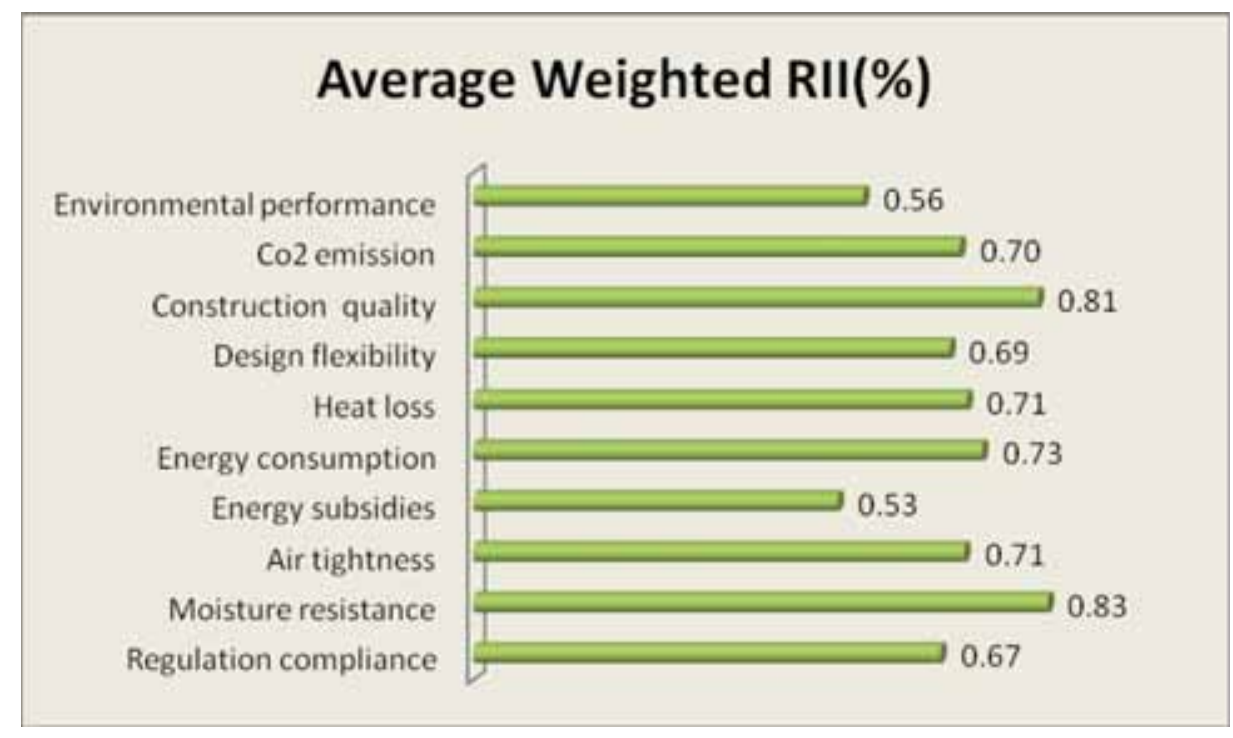

Figure 5: Ranking of average weighted RII (\%) for regulation efficiency sub-criteria. 
Besides, findings further suggest high level of awareness of sustainable performance issues among the respondents; next section tests the significance of the level of relationship between respondents' opinions on the identified sub-criteria.

\section{SIGNIFICANCE OF THEIR RELATIONSHIP}

To test the significance of their correlation relationship, the correlation coefficient, $W$ was tested at a $5 \%$ level of significance as shown in Table 3.

The hypotheses developed for the significance testing are:

Null hypothesis (Ho): Indicating that the sub-criteria are independent and there is neither relationship nor agreement among them.

Alternative hypothesis $(\mathrm{H})$ : Indicating that the sub-criteria are dependent and there is some level of agreement among them.

When testing hypotheses using Kendall's $W$ statistics, the objects are the permutable units under Ho. For the global test of significance, the rank values in all respondents are permuted at random, independently from respondent to respondent. The null hypothesis of this test is the independence of the rankings produced by all respondents. The alternative hypothesis is that at least one of the respondents is concordant with another one of them or with some of the other respondents [31, 32]. In Table 3, $\mathrm{N}$ represents number aggregated scores for sub-criteria as assessed by professional group that participated in the study, while the Sig. (two-tailed) indicates the significant level between the variables correlated. Also, indicated in the analysis was the correlation coefficient which shows the level of agreement and relationship between the building professional groups. The above test shows that the correlation among the respondents is significant with correlation coefficient ranging from 0.315 to 1.000 . There is high tendency toward 1 , which indicates strong positive correlation with $80 \%$ of correlation coefficient above 0.500 . Furthermore, correlations tested among the building professional recorded correlation significance below 0.01 significant levels. Thus it indicates some levels of agreement and strong correlation among these professionals. Hence, the null hypothesis (Ho) which indicates that the sub-criteria are independent and there is neither relationship nor agreement among the criteria is therefore rejected. Thus, it shows that the sub-criteria are dependent and there is some level of agreement among the respondents. Also, it provided a platform for the leading sub-criteria from the survey to be included in the integrated sustainable performance model. Furthermore, the Figs 6 and 7 below show the types of correlation relationship recorded among the building professionals' opinions on sub-criteria tested for sustainable performance indicators. The figures show that the correlation relationship between these respondents' opinions is positive and there is some level of agreement among the building professional. This can be seen especially among engineers and contractors, engineers and project managers. Having shown the correlation relationships and tested the significance of the relationships, it can therefore be concluded that there is some level of consensus from the respondents on some of the essential sub-criteria identified for sustainable performance indicators toward residential envelope sustainable performance modeling.

It is therefore necessary to further analyze the significance of the consensus and the relationship existing between the respondent using regression analysis.

\subsection{Regression analysis}

Tables 4 and 5 further analyzed that the level of association and relationship that exists from the participating respondents on the identified sub-criteria is significant. In Table 4, the results indicate that a significant correlation and relationship between variables analyzed. The R-value is very high at 0.82 , which indicates a very strong relationship between the dependent variable, (engineer) and 


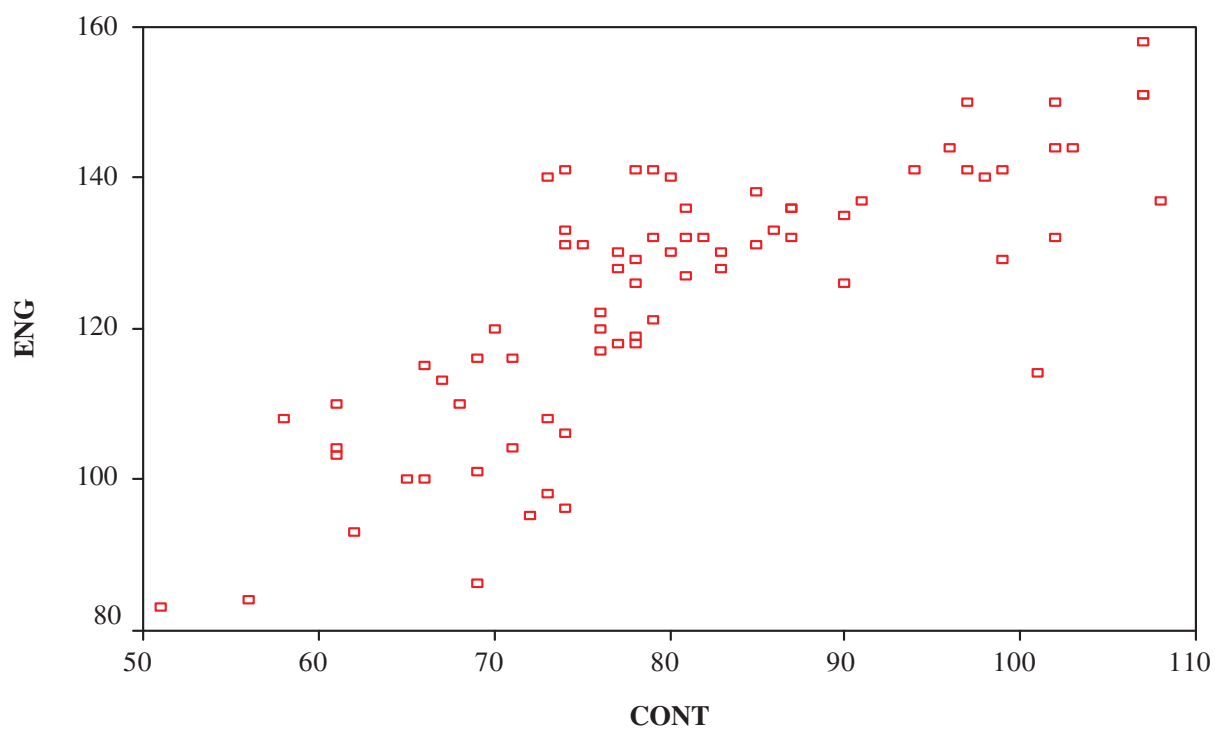

Figure 6: Correlation relationships between engineer and contractor.

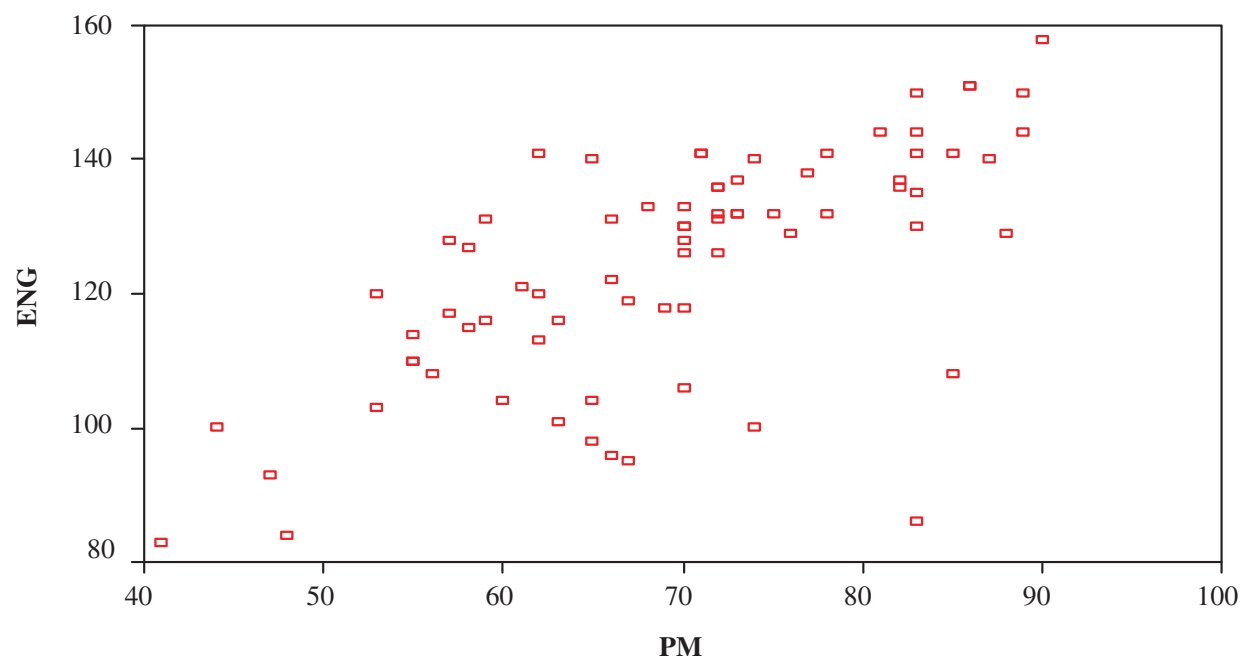

Figure 7: Correlation relationships between engineer and project manager.

independent variables (contractor, quantity surveyor, project manager, consultant, environmentalist, and others). Thus, it suggests high level of awareness from these respondents and that the higher response value from these respondents will produce higher response value from engineer. Moreover, the $\mathrm{R}^{2}$ value in Table 4 is 0.67 which indicates that $67 \%$ of variance on engineers' opinions can be accounted for by these independent variables listed above. Thus, it suggests a strong relationship and association between them. The F and associated $p$ value (Sig. F) which is 19.59 and 0.000 , 
Table 4: Regression model summary.

\begin{tabular}{|c|c|c|c|c|c|c|c|c|c|}
\hline \multirow[b]{2}{*}{ Model } & \multirow[b]{2}{*}{$\mathrm{R}$} & \multirow[b]{2}{*}{$\mathrm{R}$ square } & \multirow[b]{2}{*}{$\begin{array}{l}\text { Adjusted } \\
\text { R square }\end{array}$} & \multirow[b]{2}{*}{$\begin{array}{l}\text { Std. error of } \\
\text { the estimate }\end{array}$} & \multicolumn{5}{|c|}{ Change statistics } \\
\hline & & & & & $\begin{array}{l}\text { R square } \\
\text { change }\end{array}$ & F change & df1 & df 2 & $\begin{array}{l}\text { Sig. F } \\
\text { change }\end{array}$ \\
\hline 1 & 0.820 & 0.672 & .638 & 10.45940 & 0.672 & 19.594 & 7 & 67 & 0.000 \\
\hline
\end{tabular}

a. Predictors: (Constant), OTHERS, ENV, ARCH, QS, PM, CONT, CONST.

b. Dependent Variable: ENG.

respectively, in Table 4 indicates that the overall relationship between engineers and others respondents is significant. Hence, alternative hypothesis $(\mathrm{H})$ indicates that the sub-criteria are dependent and that there is some level of agreement among them is further supported. Besides, in Table 5, under standardized coefficient, the beta value for each independent variable (contractor, quantity surveyor, project manager, consultant, environmentalist, and others) is presented. In the regression model, contractor has the highest standardized regression coefficient, 0.45 , which indicates the strength of association between the engineers and contractors on the sub-criteria identified for building envelope sustainable performance indicators. This is closely followed by quantity surveyor with 0.16 , others respondents, 0.14 , project manager, 0.038 , environmentalist, 0.043 , consultant, 0.066 , and architect with 0.040 standardized regression coefficient. Thus, it shows a significant relationship between engineers' opinions and other respondents (independent variables) in the model.

In Fig. 8 where engineer was assumed to be dependent variable, the standardized regression coefficient was 1.02 which suggests that the strength of association between the engineers and contractors on the sub-criteria identified for building envelope sustainable performance indicators is very high. Also, the $\mathrm{R}^{2}$ value in Fig. 8 is 0.62 which indicates that $62 \%$ of variance on engineers' opinions can be accounted for by the independent variable contractor. Thus, it suggests a strong positive relationship and association between them.

Likewise in the Fig. 9 where engineer was also assumed to be dependent variable, the standardized regression coefficient was 1.66 which indicated that the strength of association between the engineers and consultants on the identified sub-criteria for building envelope sustainable performance is very high. Also, the $\mathrm{R}^{2}$ value as recorded in Fig. 9 is 0.45 which indicates that $45 \%$ of variance on engineers' opinions can be accounted for by the independent variable consultant. Thus, it suggests a strong positive relationship and association between them as well.

In the case of Fig. 10, contractor was assumed to be dependent variable, while project manager served as independent variable. The standardized regression coefficient recorded was 0.85 which suggested that the strength of association between the contractors and project managers on the subcriteria identified for building envelope sustainable performance indicators is very high. Also, the $\mathrm{R}^{2}$ value in Fig. 10 was 0.54 which indicates that $54 \%$ of variance on contractor's opinion can be accounted for by the independent variable project manager. This also suggested a strong positive relationship and association between them.

These results are fairly comparable and thus suggest that there is significant relationship between them. Also, it means that the response values from other respondents (building and construction professionals) can be used to predict the response values that can be obtained from engineer and contractor. Besides, it means that Null hypothesis (Ho) which indicates that the sub-criteria are independent and there is neither relationship nor agreement among them is rejected, while alternative 


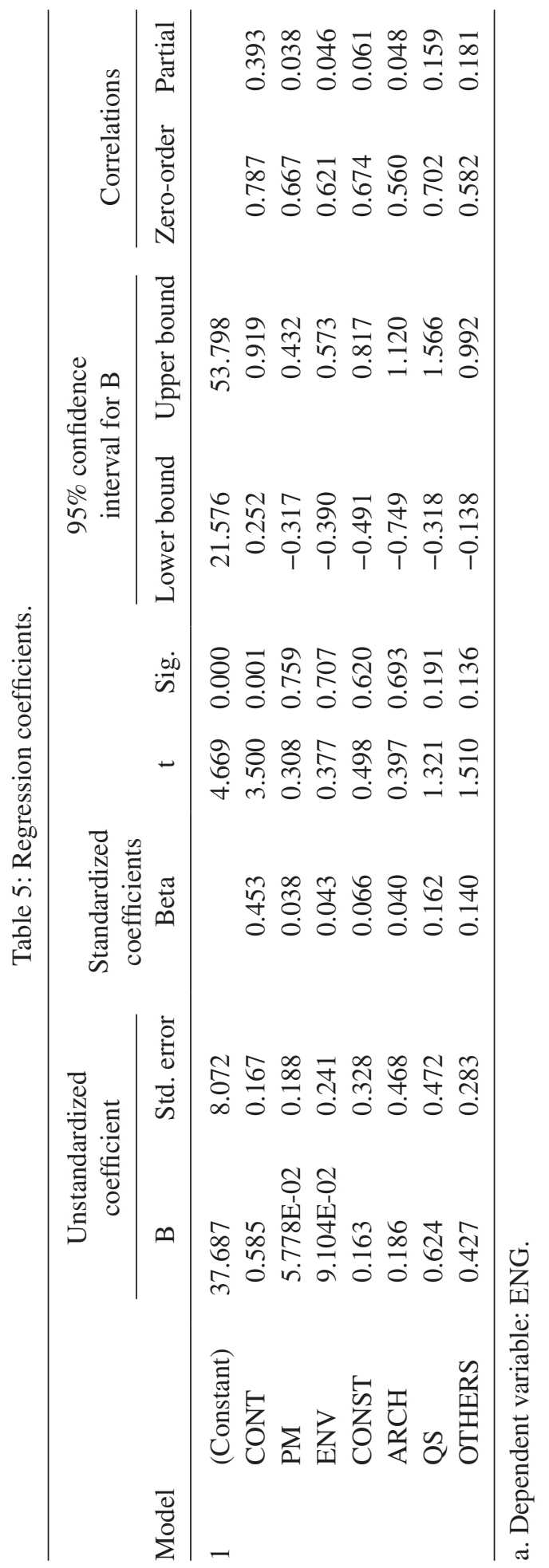




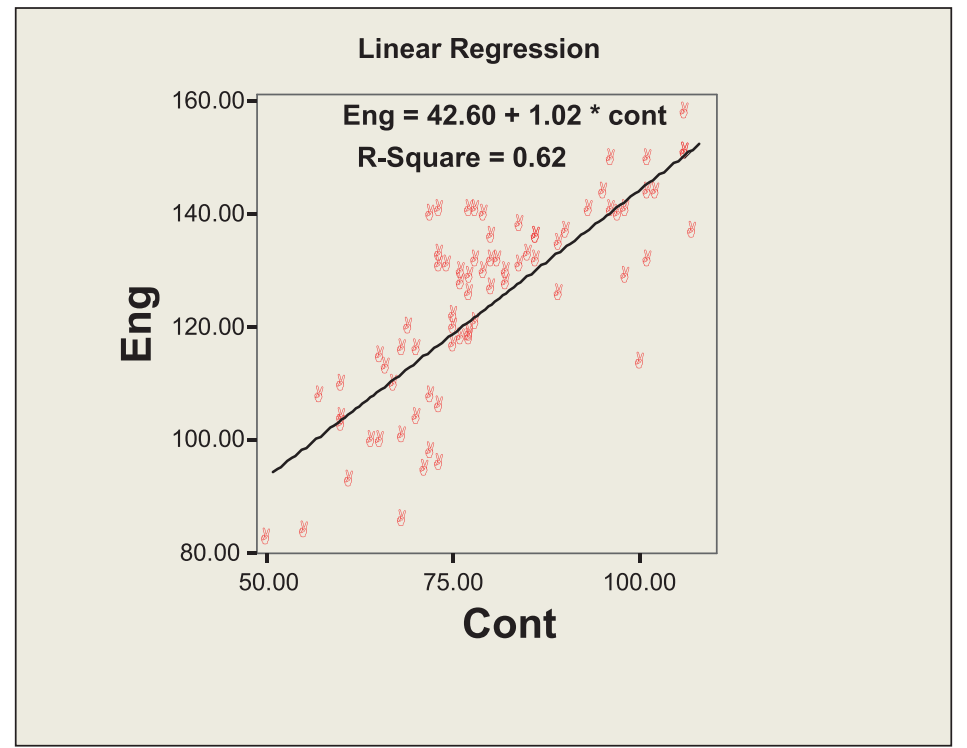

Figure 8: Correlation relationships between contractor and consultant.

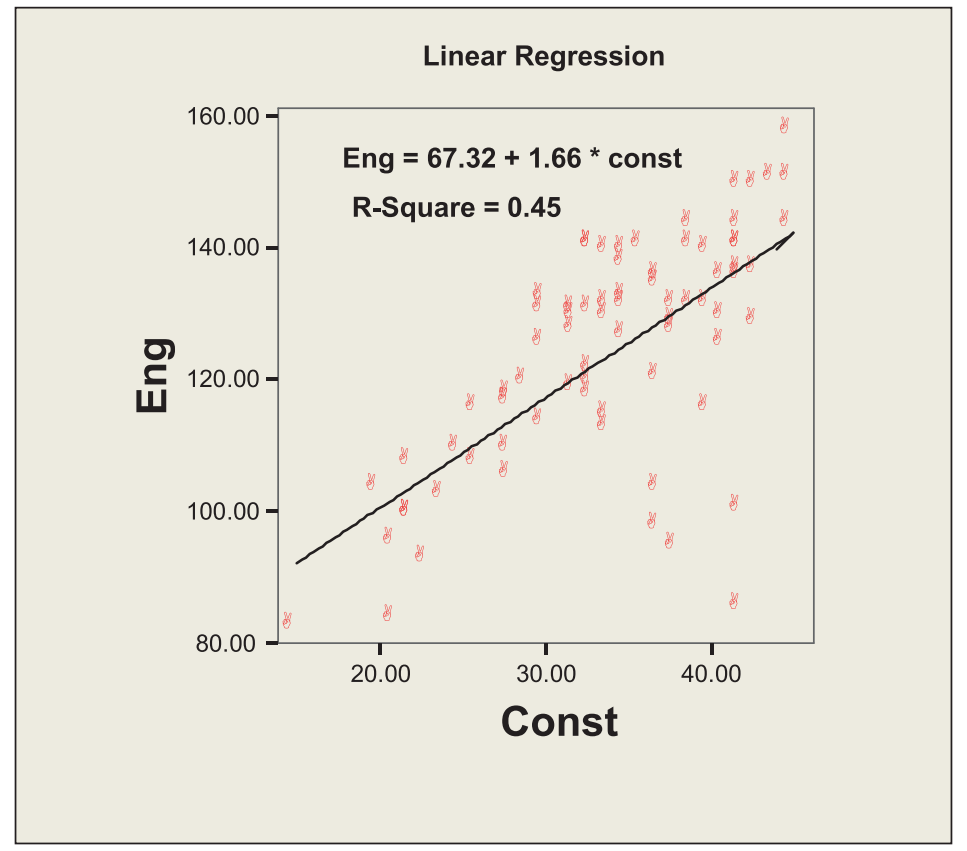

Figure 9: Correlation relationships between contractor and consultant.

hypothesis $(\mathrm{H})$ which indicates that the sub-criteria are dependent and there is some level of agreement among them is thereby accepted. Overall, this section has successfully established the essential sustainable performance sub-criteria that can be used to measure the sustainable performance on building envelope. In addition, the section tested the significance of respondents' levels of agreement 


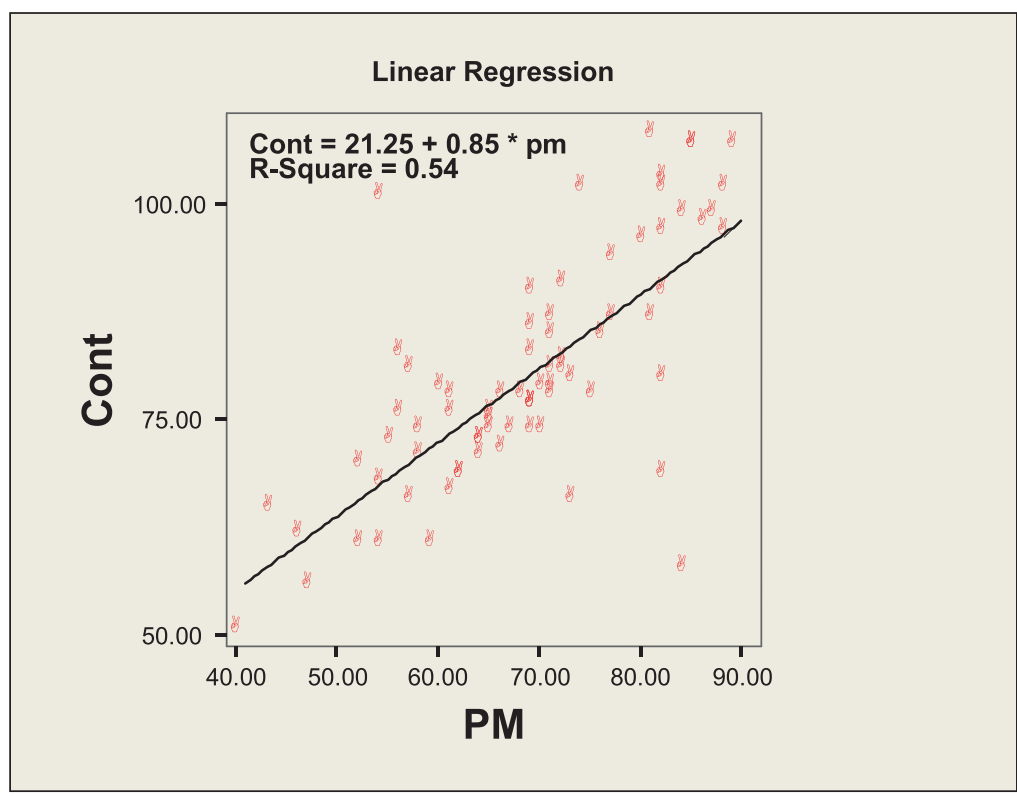

Figure 10: Correlation relationships between contractor and consultant.

and relationship on these modeling criteria to provide a platform for an integrated sustainable performance appraisal in building envelope development.

\section{RESULTS AND DISCUSSION}

In this study, sub-criteria that can be incorporated for the assessment of sustainable energy performance indicators were investigated. The sustainable performance indicators of which their sub-criteria were investigated include: energy efficiency, energy regulation, environmental impact, material efficiency, and external benefit. In Table 2, energy consumption and 11 other issues came up as the most important issues to be assessed for building envelope sustainable performance under energy efficiency indicator. This finding can be attributed to the interconnection between building energy efficiency, energy consumption, and building components. If the building components are made sustainable, energy consumption will be reduced while energy efficiency of that building will be enhanced. Energy efficiency measures for buildings are approaches through which the energy consumption of a building can be reduced while maintaining or improving the level of comfort in the building. For this reason, energy efficiency in buildings, particularly residential building envelope is considered an important factor for building sustainability [4, 33-37]. Besides, the actual amount of energy consumed by building envelope will depend on many factors known as sub-criteria, such as the design of the building envelope, design of the building, orientation, outside temperature, conservation approaches, glazing system, window areas, light systems, types of equipment and appliance air conditioning and ventilation, level of insulation, and the thermal characteristics of walls and roofs. In view of these facts, the envelope energy consumption is linked to entire building energy consumption [20, 34, 38-42]. Moreover, operational energy is also considered an important factor for achieving energy efficiency in building development [43-46]. It is the energy used for heating, cooling, ventilating, lighting, powering appliances, and equipment in building [37, 44, 46, 47]. Other 
issues identified received significant level of importance from respondents which is fairly comparable with energy consumption, energy conservation, and energy subsidies and policy. This level of performance thus qualified them as important sub-criteria for measuring the sustainable performance of building envelope.

As energy efficiency of building envelope cannot be measured in isolation, other important subcriteria were identified in Fig. 2 under material efficiency indicator. The finding from Fig. 2 indicates that durability is the most important criteria for sustainable performance assessment of building envelope along with 11 other factors. Other leading issues identified include: recycling potential; energy saving potential and indoor air quality. These criteria were supported by Energy Policy Act of 2005 [48] which identified durability, energy efficiency, life cycle performance, and occupant productivity as important attributes of building sustainable performance. This view was echoed by the US building enclosure community in 2008 when they launched a formal initiative which emphasized the linkages between energy efficiency, durability and the quality of the indoor environment [49] as an important issue for building sustainability. Furthermore, in Fig. 3 under environmental impact, the importance of air pollution in measuring the sustainable performance of building envelope was stressed. Air pollution issue came first, closely followed by material emission, depletion of renewable resources, energy consumption, deforestation impact, and five other important environmental issues were identified as important issues to be assessed for building envelope sustainable performance under environmental impact indicator. The find explained the important link between material and environment in term of resources consumption, pollution, emission, and depletion. Thus, it suggests that the choice of material used in the construction of a building has a direct impact on the environment [50]. The issues identified as sub-criteria under environmental impact indicator were consistent with those identified by Urher [51]. The author points out that the buildings contribute significantly to the environmental burden, quoting Levin [52] for the following contribution levels: use of raw materials (30\%), energy (42\%), water (25\%), and land (12\%), and pollution emission such as atmospheric emissions (40\%), water effluents $(20 \%)$, solid waste $(25 \%)$, and other releases (13\%). The impact of building development on the environment majorly results from pollutants, energy consumption, water consumption, land degradation/consumption, resource consumption, waste production, and loss of biodiversity incurred throughout the life cycle of buildings, from raw material extraction, processing, construction, building operation and demolition [51]. Thus, it indicates the important of environmental impact indicator and its sub-criteria in measuring the sustainable performance of building envelope as identified in this study. In addition to the aboveidentified issues for sub-criteria, some important sub-criteria issues were also identified under external benefits, as shown in Fig. 4. Under external benefit, air quality issue came first, following by environmental ecological value, landscape beautification, environmental economical value, and five other factors. These factors received significant level of importance from respondents. The findings from Fig. 4 suggest the importance of social sustainability consideration in sustainable performance assessment. Other important issues identified for measuring sustainable performance of building envelope from Fig. 5 include heat loss, moisture resistance, and construction quality along with five other building regulation issues. They were identified as important sub-criteria issues to be assessed under regulation efficiency indicator for measuring building envelope sustainable performance.

Moreover, in Tables 3-5 the hypothesis $(\mathrm{H})$ which indicates that the sub-criteria are dependent and there are some levels of agreement among them is confirmed. This finding indicates that the level of relationship between respondent is significant. This can be further seen in the strength of relationship between the respondents with contract (CONT) having the highest strength of 0.45 . In addition Figs 6 and 7 indicate positive relationship among the respondents on the identified sub-criteria, while Figs 8-10 
show that significant amount of engineer's opinion on the identified sub-criteria can be predicted with other respondents' opinions such contractor, project manager, consultant, environmentalist, quantity surveyor, and others. Hence, this study has successfully created effective sub-criteria that could be assessed under sustainable energy performance indicators to be incorporated for building assessment performance methods. This effort will help to enhance the capability of building performance assessment methods and promote building envelope sustainability.

\section{CONCLUSIONS}

The sustainability of building envelope therefore requires more than a simple focus on energy consumption over the lifespan of the building. This was based on the fact that there are some many factors responsible for the sustainable performance of building development. But, since so many factors are used in building construction, the issue of sustainability and sustainable performance of the building envelope becomes highly complex. The study has identified sub-criteria that can be used in assessing and measuring the sustainable performance of building envelope development. The level of agreement from respondents on these sub-criteria identified as shown from the correlation and regression analysis conducted in this study is very significant and positively correlated. The levels of their correlation coefficient were very high which again confirmed high level of relationship among the respondents. Overall, based on the significance of experts' opinions and hypothesis tested, the study therefore concluded that these sub-criteria are the essential criteria to be incorporated for modeling the sustainable performance of residential building envelope. However, further research still need to be done to investigate the level of interaction between the identified subcriteria. The summary of the sub-criteria identified is as follows:

Energy efficiency: energy consumption, operational energy, energy subsidies and government policy, energy conservation, building envelope design, window and door glazing, wall insulation, door and window frame, building appliance and equipment, labeling and certification, depletion of renewable resources, and depletion of non-renewable resources.

Material efficiency: recycling potential of envelope materials, energy saving potential, potential to improve indoor air quality, high moisture resistance, material life span, low pollution effect, minimal emission, low maintenance, minimum heat gain, and renewable potential and material flexibility.

Environmental impact: air pollution, material emission, depletion of renewable resources, energy consumption, deforestation impact, depletion of non-renewable resource, construction waste, indoor air quality, carbon emission, and noise pollution.

External benefit: indoor air quality, environmental ecological value, landscape beautification, environmental economical value, social image, local community economy, indoor environment, environment beautification, user productivity, and living environment.

Regulation efficiency: moisture resistance, construction quality, energy consumption, heat loss, air tightness, $\mathrm{CO}_{2}$ emission, design flexibility, and regulation compliance.

\section{REFERENCES}

[1] Jan, H. \& Harputlugil1, G.U., The relation between building assessment systems and building performance simulation, 2010.

[2] Kibert, C.J., High Performance Green Building, unpublished book draft, available from http:// web.dcp.uff.edu/ckibert/ASCEBook/index.htm, (last accessed December, 2010).

[3] Mwasha, A., Williams, R. \& Iwaro, J., Modeling the performance of residential building envelope: the role of sustainable energy performance indicators. Energy and Buildings, 43(9), pp. 2108-2117, 2011. doi: http://dx.doi.org/10.1016/j.enbuild.2011.04.013 
[4] Saidur, R., Energy consumption, energy savings, and emission analysis in Malaysian office buildings. Energy Policy, 37, pp. 4104-4113, 2009. doi: http://dx.doi.org/10.1016/j.enpol. $\underline{2009.04 .052}$

[5] Anon., Ninth Malaysian Plane 2006-2010, The Economic Planning Unit Prime Minister's Department. Putrajaya, Malaysia, 2006.

[6] Baragatti, Tallerde Ciencia, Tecnología y Ambiente en las Actividades del Sector Energético, Bs.As., Agosto de, 2004.

[7] DeDicco, R., Presentey future dela disponibilidaddel gas natural Argentino, IDICSO. Areade Recursos Energeticosy Planificaciónparael Desarrollo, 2005, available at http://www.salvador. edu.ar/csoc/idicso/energia/energia.htmS.

[8] Al-Homoud, Mohammad S. Performance characteristics and practical applications of common building thermal insulation materials. Building and environment, 40, pp. 353-366, 2005. doi: http://dx.doi.org/10.1016/j.buildenv.2004.05.013

[9] Al-Homoud, Mohammad S. \& Iqbal, I. Parametric analysis of alternative energy conservation measures in an office building in hot and humid climate. Building and Environment, 42, pp. 2166-2177, 2007. doi: http://dx.doi.org/10.1016/j.buildenv.2006.04.011

[10] Hegger, M., Mathias, F., Thomas, S. \& Martin, Z. Energy Manual: Sustainable Architecture, 1st German edn., German national Library: Munich, 2008.

[11] Horman, Michael, Sinem, Korkmaz \& David, Riley, Piloting evaluation metrics for sustainable high-performance building project delivery. Journal of Construction Engineering and Management, ASCE, 136(8), p. 877, 2010. doi: http://dx.doi.org/10.1061/(ASCE)CO.19437862.0000195

[12] Dimitris, A., Giama, E. \& Papadopoulos, A., An assessment tool for the energy, economic and environmental evaluation of thermal insulation solutions. Energy and Buildings, 41, pp. 1165-1171, 2009. doi: http://dx.doi.org/10.1016/j.enbuild.2009.06.003

[13] Giama, E. \& Papadopoulos, A.M., Rating systems for counting buildings' environmental performance. International Journal of Sustainable Energy, 28(1-3), pp. 29-43, 2009.

[14] Hill, R.C. \& Bowen, P.A., Sustainable construction: principles and a framework for attainment. Construction Management and Economics, 15, pp. 223-239, 1997. doi: http://dx.doi. org/10.1080/014461997372971

[15] Chen, Z., LI, H. \& Wong, T.C., Environmental management of urban construction projects in China. Journal of Construction Engineering and Management, 126(4), pp. 320-324, 2000. doi: http://dx.doi.org/10.1061/(ASCE)0733-9364(2000)126:4(320)

[16] Shen, L.Y. \& Tam, W.Y.V., Implementing of environmental management in the Hong Kong construction industry. International Journal of Project Management, 20(7), pp. 535-543, 2002. doi: http://dx.doi.org/10.1016/S0263-7863(01)00054-0

[17] Shen, L.Y., Tam, W.Y.V., Chan, C.W.S. \& Kong, S.Y.J., An examination on the waste management practice in the local construction site. Hong Kong Surveyors, 13(1), pp. 39-48, 2002.

[18] Tam, W.Y.V., Tam, C.M., Tsui, W.S. \& HO, C.M., Environmental indicators for environmental performance assessment in construction. Journal of Building and Construction Management, 10, pp. 46-56, 2006.

[19] Tam, W.Y.V., Tam, C.M., Zeng, S.X. \& Chan, K.K., Environmental performance measurement indicators in construction. Building and Environment, 41(2), pp. 164-173, 2005. doi: http:// dx.doi.org/10.1016/j.buildenv.2005.01.009

[20] Chow, L.C., A study of sectoral energy consumption in Hong Kong (1984-97) with special emphasis on the household sector. Energy Policy, 29, pp. 1099-1110, 2001. doi: http://dx.doi. org/10.1016/S0301-4215(01)00046-5 
[21] Foley, B., Daniell, A. \& Trevor, M.A., Sustainability tool for intrasectoral and intersectoral water resources decision making. Australian Journal of Water Resources, 8, pp. 11-19, 2004.

[22] Norman, W. \& MacDonald, C., Getting to the bottom of triple bottom line. Business Ethics Quarterly, 14, pp. 243-262, 2004. doi: http://dx.doi.org/10.5840/beq200414211

[23] George, C. \& Kirkpatrick, C., Impact Assessment and Sustainable Development: European Practice and Experience, Edward Elgar Publishing: London, UK, 2007. doi: http://dx.doi. org/10.4337/9781847205407

[24] Karol, P. \& Brunner, J., Tools for measuring progress towards sustainable neighborhood environments. Sustainability, 1, pp. 612-627, 2009. doi: http://dx.doi.org/10.3390/su1030612

[25] Singh, R.K., Murty, H.R., Gupta, S.K. \& Dikshit, A.K., An overview of sustainability assessment methodologies. Ecological Indicator, 9, pp. 189-212, 2009.

[26] Hak, T., Moldan, B. \& Dahl, A.L., Sustainability Indicators: A Scientific Assessment, Island Press: Washington, DC, USA, 2007.

[27] Hacking, T. \& Guthrie, P., A framework for clarifying the meaning of triple bottom-line: integrated, and sustainability assessment. Environmental Impact Assessment Review, 28, pp. 73-89, 2008. doi: http://dx.doi.org/10.1016/j.eiar.2007.03.002

[28] Yigitcanlar, T. \& Dur, F., Developing a sustainability assessment model: the sustainable infrastructure, land-use, environment and transport model. Sustainability, 2(1), pp. 321-340, 2010. doi: http://dx.doi.org/10.3390/su2010321

[29] SuperSurvey, Online Survey Response Rates and Times Background and Guidance for Industry. Ipathia, Inc./ SuperSurvey available from http://www.supersurvey.com/cited 2011.

[30] Tam, C.M., Tam, W.Y.V. \& Zeng, S.X., Environmental performance evaluation for construction. Building Research and Information, 30(5), pp. 349-361, 2002. doi: http://dx.doi. org/10.1080/09613210210150964

[31] Siegel, S., \& Castellan N.J., Nonparametric Statistics for the Behavioral Sciences, (2nd edn.), McGraw-Hill: NewYork, 1988.

[32] Pierre, L. Species associations: the Kendall coefficient of concordance revisited. Journal of Agricultural, Biological, and Environmental Statistics, 10(2), pp. 226-245, 2005. doi: http:// dx.doi.org/10.1198/108571105X46642

[33] Lombard, L.P., Jose, O. \& Christine, P., A review on buildings energy consumption information. Energy and Building, 40(3), pp. 394-398, 2008. doi: http://dx.doi.org/10.1016/j. enbuild.2007.03.007

[34] Yang, L., Lam, J.C,. \& Tsang, C.L., Energy performance of building envelopes in different climate zones in China. Applied Energy, 85(9), pp. 800-817, 2008. doi: http://dx.doi. org/10.1016/j.apenergy.2007.11.002

[35] Yamtraipat, N., Khedari, J., Hirunlabh, J. \& Kunchornrat, J., Assessment of Thailand indoor set-point impact on energy consumption and environment. Energy Policy, 34(7), pp. 765-770, 2006. doi: http://dx.doi.org/10.1016/j.enpol.2004.07.009

[36] Morel, J.C., Mesbah, A., Oggero, M. \& Walker, P., Building houses with local materials: means to drastically reduce the environmental impact of construction. Building and Environment, 36(10), pp. 1119-1126, 2001. doi: http://dx.doi.org/10.1016/S0360-1323(00)00054-8

[37] Ding, G., The development of a multi-criteria approach for the measurement of sustainable performance for built projects and facilities, Ph.D. Thesis, University of technology, Sydney, Australia, 2004.

[38] Omar, M.A. \& Mohammed, M.A., A survey of energy-efficient strategies for effective air-conditioning. Energy Conversion and Management, 45, pp. 1643-1654, 2004. doi: http://dx.doi. org/10.1016/j.enconman.2003.10.004 
[39] Jaber, J.O., Mohsen, M.S. \& Al-Sarkhi Akash, B., Energy analysis of Jordan's commercial sector. Energy Policy, 31, pp. 887-894, 2003. doi: http://dx.doi.org/10.1016/S0301-4215 (02)00132-5

[40] Farhanieh, B. \& Sattari, S., Simulation of energy saving in Iranian buildings using integrative modelling for insulation. Renewable Energy, 31, pp. 417-425, 2006. doi: http://dx.doi. org/10.1016/j.renene.2005.04.004

[41] Uchiyama, Y., Present efforts of saving energy and future energy demand/supply in Japan. Energy Conversion and Management, 43, pp. 1123-1131, 2002. doi: http://dx.doi.org/10.1016/ $\underline{\text { S0196-8904(02)00003-1 }}$

[42] Radhi, H., A systematic methodology for optimizing the energy performance of buildings in Bahrain. Energy and Buildings, 40(7), pp. 1297-1303, 2008. doi: http://dx.doi.org/10.1016/j. enbuild.2007.11.007

[43] West, J., Assessing the worth of embodied energy. Building service, p. 49, 1995.

[44] Treloar, G., Fay, R., Ilozor, B. \& Love, P., Building materials selection: greenhouse strategies for built facilities. Facilities, 19(3/4), pp. 139-149, 2001. doi: http://dx.doi. org/10.1108/02632770110381694

[45] Pullen, S., Energy used in the construction and operation of houses. Architectural Science Review, 15(3), p. 87, 2000.

[46] Chen, T.Y., Burnett, J. \& Chau, C.K., Analysis of embodied energy use in the residential building of Hongkong. Energy, 26, pp. 323-340, 2001. doi: http://dx.doi.org/10.1016/S03605442(01)00006-8

[47] Treloar, G., Fay, R. \& Iyer-Raniga, U., Life-cycle energy analysis of buildings: a case study, Building Research \& Information, 28(1), pp. 31-41, 2000. doi: http://dx.doi.org/ $\underline{10.1080 / 096132100369073}$

[48] Energy Policy Act of 2005; Public Law; EPA: Washington, DC, USA, 8: 109-58, 2009 Available online: http://www.epa.gov/oust/fedlaws/publ_109-058.pdf (accessed on 1 July 2009).

[49] Bomberg, M. \& Onysko, D., Energy efficiency and durability of buildings at the crossroads. Journal of Building Enclosure Design. Summer/Fall, pp. 27-35, 2008.

[50] Collet, F., Serres, L., Miriel J. \& Bart, M., Study of thermal behaviours of clay wall facing south. Building and Environmnet, 41, pp. 307-315, 2006. doi: http://dx.doi.org/10.1016/j. buildenv.2005.01.024

[51] Uher, T.E., Absolute indicator of sustainable construction, in Proceedings of COBRA 1999, RICS Research Foundation, RICS: London, pp. 243-253, 1999.

[52] Levin, H., Systematic evaluation and assessment of building environmental performance (ASEABEP). Proc. Second International Conference on Buildings and the Environment, CSTB and CIB, 2, Paris, June, 3-10,1997. 